\title{
Evaluation of the corrosion resistance of SAF 2205 steel ageing at low temperatures during 3000 and 5000 hours
}

\author{
João Roberto Sartori Moreno* Paulo Cezar Tulio \\ Mechanical Engineering Department, Universidade Tecnológica Federal do Paraná - UTFPR, Av. Alberto Carazzai, \\ 1640 - Cornélio Procópio/PR, - Zip Code 86300-000, Brazil.
}

Accepted 6 November, 2013

\begin{abstract}
The corrosion properties of duplex stainless steel type SAF 2205 after long-term ageing at $300^{\circ} \mathrm{C}$ and $400^{\circ} \mathrm{C}$ were investigated. However, these steels show a degradation of their properties as submitted by long time, in low temperatures about 280 to $520^{\circ} \mathrm{C}$. This work describes this behavior by analysis of the resistance to general corrosion of the SAF 2205 steel ageing in the temperatures $300^{\circ} \mathrm{C}$ and $400^{\circ} \mathrm{C}$, during 2000,3000 and $5000 \mathrm{~h}$, for sample aged at $400^{\circ} \mathrm{C}$ for $5000 \mathrm{~h}$. The experimental techniques used were the potential dynamic curves (EPR-Double Loop), scanning and transmission electronic microscopy for microstructure analysis and weight loss test. It is verified that the ageing treatments modify the corrosion resistance due to microstructural changes of precipitation in the matrix and not by precipitation in grain boundaries (sensitization). However the sample aged at $400^{\circ} \mathrm{C}$ for $5000 \mathrm{~h}$, due to the precipitation of phases $G$ and $\alpha^{\prime}$, showed an appreciable increase in the loss of mass.
\end{abstract}

Key words: ageing, precipitation, corrosion, weight loss, EPR.

\section{INTRODUCTION}

The combination of individual properties of each of the phases of the duplex stainless steel (austenite and ferrite), ensure greater use and replacement of conventional stainless steels for these materials. These steels have been recommended for applications in chemical and petrochemical plants, pulp and paper reports. This is certainly due to the characteristics of good mechanical strength, weldability and machinability coupled with good resistance corrosion of these steels in normal use.

However, it is known that these materials when subjected to a temperature range of 280 to $520^{\circ} \mathrm{C}$ according to Ghosh et al. (2008), suffer loss of toughness and effects of loss of resistance corrosion when treated for times of the order of $100 \mathrm{~h}$ at intermediate temperatures around $475^{\circ} \mathrm{C}$ have been studied and assigned to the precipitation phase $\alpha^{\prime}$ in the ferritic matrix second (lacoviello et al., 2005). The degrading effect of the properties of these steels are due to precipitation of G-phase, rich in Si and $\mathrm{Cr}$ according to Han et al. (2009), and studies of the effects of prolonged times, around $5000 \mathrm{~h}$ at intermediate temperatures between $300^{\circ} \mathrm{C} / 400^{\circ} \mathrm{C}$, confirm changes to the corrosion resistance of duplex stainless steels. Thus, this study aims to identify the behaviors of corrosion resistance duplex steel type SAF 2205 as mentioned by Zhang et al. (2009) ageing for long times by comparative electrochemical techniques and immersion.

\section{MATERIALS AND METHODS}

Samples were taken from rolled steel bars SAF 2205, whose chemical composition is shown in Table 1. The procedure for metallographic analysis proceeded as ASTM A-262 Practice A, followed by scanning electron microscope (SEM) and transmission (TEM), which identified the microstructure characteristic 
Table 1. Chemical composition of steel SAF 2205.

\begin{tabular}{lcccccccc}
\hline Steel & \%C & \%Si & \%Mn & \%Mo & $\% S$ & $\% \mathbf{C r}$ & $\% \mathbf{N i}$ & $\% \mathbf{N}$ \\
\hline SAF2205 & 0.029 & 0.35 & 1.57 & 2.54 & 0.003 & 22.53 & 5.36 & 0.113 \\
\hline
\end{tabular}

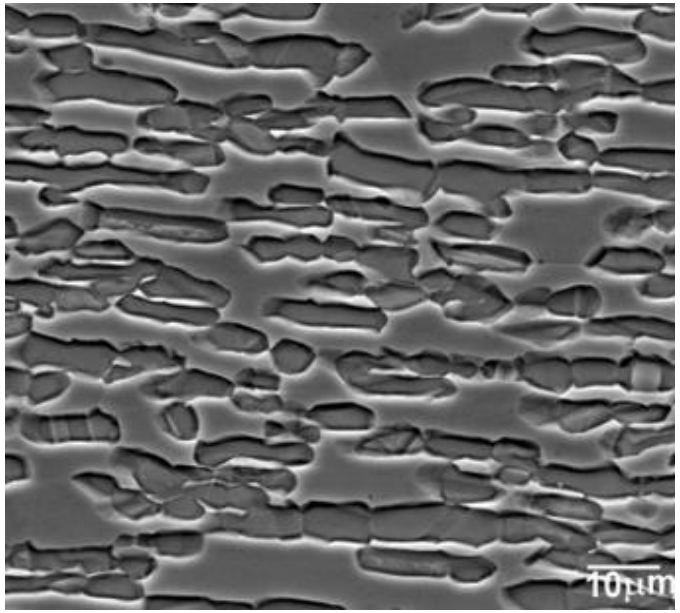

Figure 1 - Micrograph of sample as received (CR), analyzed via SEM. Attack: Oxalic Acid 10\%, $1 \mathrm{~A} / \mathrm{cm}^{2}$ for $1.5 \mathrm{~min}$.

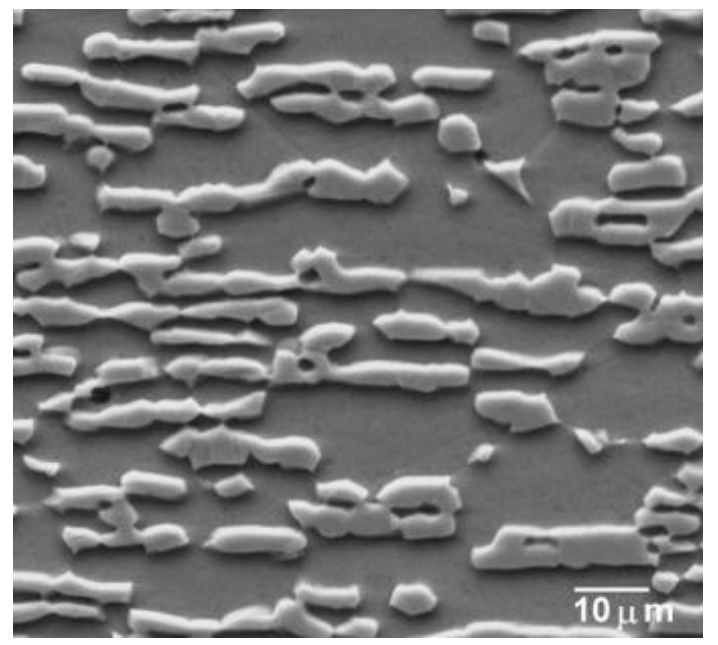

Figure 2 - Micrograph of sample treated by $300^{\circ} \mathrm{C}$ for $5000 \mathrm{~h}$, analyzed via SEM. Attack: Oxalic Acid $10 \%, 1 \mathrm{~A} / \mathrm{cm}^{2}$ for $1.5 \mathrm{~min}$.

of steel in the as-received (AS) and the states treated. Testing for verification of mass loss was held in immersion in $\mathrm{FeCl}_{3} 10 \%$ at $60^{\circ} \mathrm{C}$ for $1 \mathrm{~h}$ in an aerated medium. Also, the evaluation of intergranular corrosion susceptibility followed the method of potentiodynamic reactivation (DL-EPR). All these tests were conducted on samples of steel type SAF 2205 identified by parentheses in sequence, according to the treatment condition: as received (AS); treated for $2000 \mathrm{~h}$ at $300^{\circ} \mathrm{C}(23) ; 2000 \mathrm{~h}$ at $400^{\circ} \mathrm{C}$
(24), $3000 \mathrm{~h}$ at $300^{\circ} \mathrm{C}(33) ; 3000 \mathrm{~h}$ at $400^{\circ} \mathrm{C}(34) ; 5000 \mathrm{~h}$ at $300^{\circ} \mathrm{C}$ (53); $5000 \mathrm{~h}$ at $400^{\circ} \mathrm{C}(54)$; treated at $650^{\circ} \mathrm{C}(650)$ and $850^{\circ} \mathrm{C}(850)$ by $1 \mathrm{~h}$ respectively.

\section{RESULTS}

Figures 1 and 2 show SEM micrographs of samples as received (AS) and treated for $5000 \mathrm{~h}$ at $300^{\circ} \mathrm{C}$ (53) respectively, where we could notice the presence of complex phases in the matrix as $\alpha^{\prime}$ and $G$. The $G$ phase precipitation was identified by transmission electron microscopy and occurs manly in the ferrite phase observed by Moreno and Francisco (2013). The immersion tests shown in Figure 3 suggested that the microstructural changes really changed the behavior against corrosion, such that the differentially treated sample at $400^{\circ} \mathrm{C}$ for $5000 \mathrm{~h}(54)$ stands out against the others by the more pronounced loss. Therefore, from Figures 4 and 5 we see that the degree of sensitization (EPR-DL) and the presence of a current density of passive-active transition $\mathrm{i}_{\mathrm{a} / \mathrm{p}}$ indicate that with ageing by $5000 \mathrm{~h}$ at $400^{\circ} \mathrm{C}$ the passivation is prevented. However, lower intensity of this peak current density led to higher passivation according to Kuri et al. (2010) and as we can observe, the peak current density of the active-passive transition $i_{a / p}$, at $400^{\circ} \mathrm{C}$ presented high, leading to low passivation and favoring a greater loss of mass. Figures 6 and 7 show through an analysis by optical and TEM, another way that the sample ageing at $400^{\circ} \mathrm{C}$ for $5000 \mathrm{~h}$ (54) really suffered precipitation of chromium rich phases according to Hamaoka et al. and Shi et al. (2012), that compromised the corrosion of the steels in these conditions. We can observe that complex phases thinner as the phase $G$, are distributed more intensely by the matrix, while the phase $\alpha^{\prime}$ stage coarser stands less strongly in the matrix.

\section{DISCUSSION}

After obtaining these data it was observed that the loss of corrosion resistance of the steel SAF 2205 cannot be attributed to its sensitization when treated at low temperatures for prolonged times, but due to other precipitation distributed during ageing at long times. The effects of this ageing thermal treatment are affected by corrosive environment and time ageing. The weight loss in $\mathrm{FeCl}_{3} 10 \%$ solution, tends to always increase with exposure time in hours, showing superiority added to the sample treated at $400^{\circ} \mathrm{C}$ for $5000 \mathrm{~h}$. 


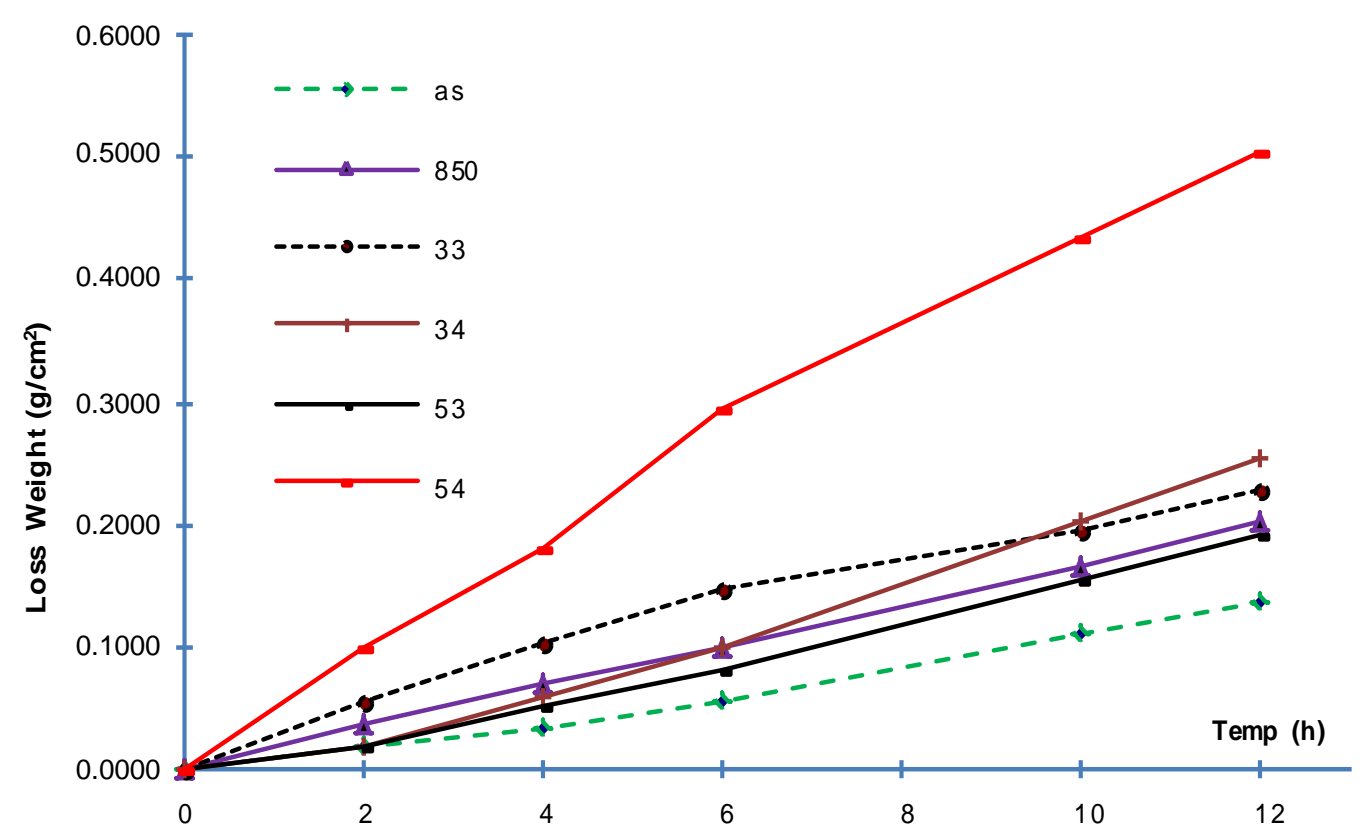

Figure 3. Mass loss as a function of time of immersion in $\mathrm{FeCl}_{3} 10 \%$ at $60^{\circ} \mathrm{C}$ in aerated medium.

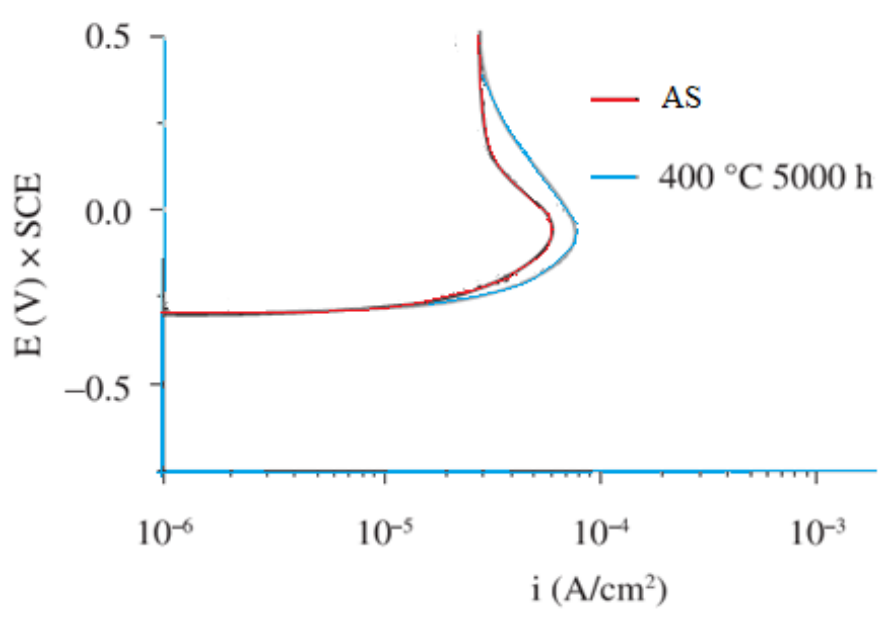

Figure 4. Partial anodic potentiodynamic curves in samples of duplex stainless steel AS and ageing at $400^{\circ} \mathrm{C}$ for $5000 \mathrm{~h}$, in solution $\mathrm{H}_{2} \mathrm{SO}_{4} ; 0.1 \mathrm{M} ; \mathrm{v}=10 \mathrm{mV} / \mathrm{s}$.

The phenomena of precipitation and coalescence of phases can be related with the decreasing and increasing tendency of corrosion resistance, respectively. The effect of ageing condition on the structural properties, mainly in the phases, is related with the phase precipitation during the ageing $G$ and a'as reported by Fang et al. (2010).

\section{Conclusion}

The thermal treatments for prolonged periods at low temperatures significantly alter the characteristics of the

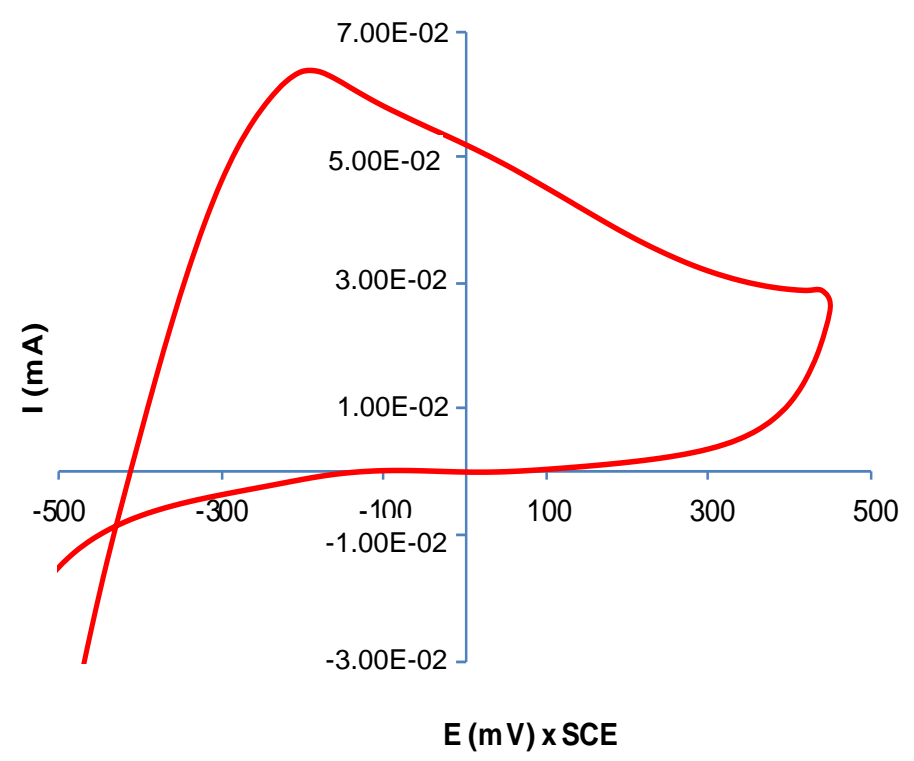

Figure 5. Checking the degree of sensitization to sample stainless steel SAF 2205, treated at $400^{\circ} \mathrm{C}$ for $5000 \mathrm{~h}$ in solution $\mathrm{H}_{2} \mathrm{SO}_{4} ; 0.1$ $\mathrm{M} ; \mathrm{v}=10 \mathrm{mV} / \mathrm{s}$.

corrosion resistance of duplex steels SAF 2205 type, but cannot be attributed to the phenomenon of the sensitization (grain boundary precipitation) because the decomposition espinodal present, is the behavioral changes responsible for the corrosion resistance of these steels, particularly when present intermetallic phases $\alpha$ ' and $\mathrm{G}$ when treated at $400^{\circ} \mathrm{C}$ for $5000 \mathrm{~h}$, as in the case of sample 54, which is highlighted with more severe weight loss. The growth of the current density of active-passive 


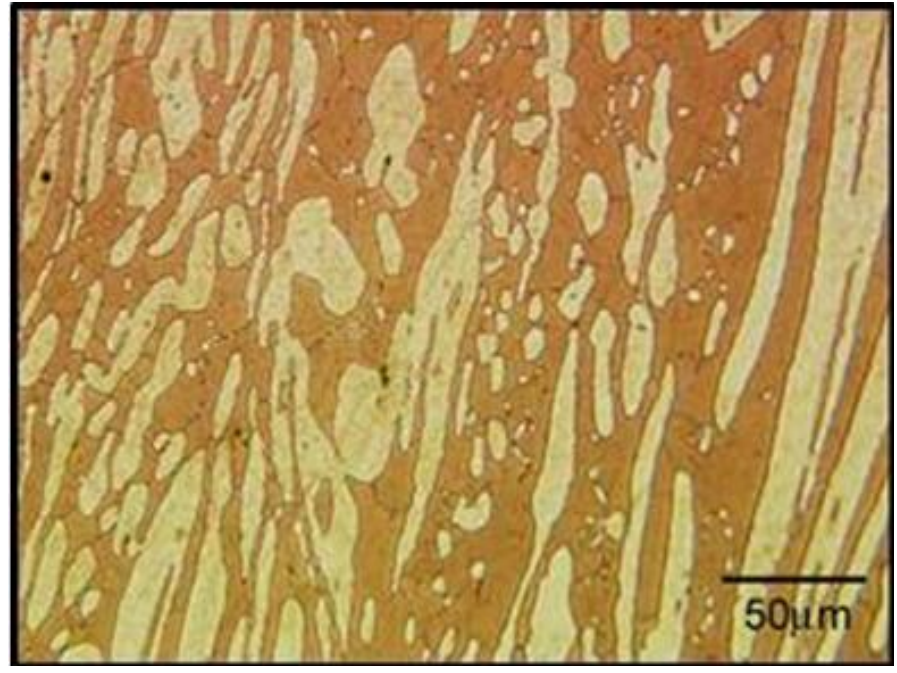

Figure 6. Optical microscopy of the sample aged at $400^{\circ} \mathrm{C}$ for 5000 h, attacked with Behara II.

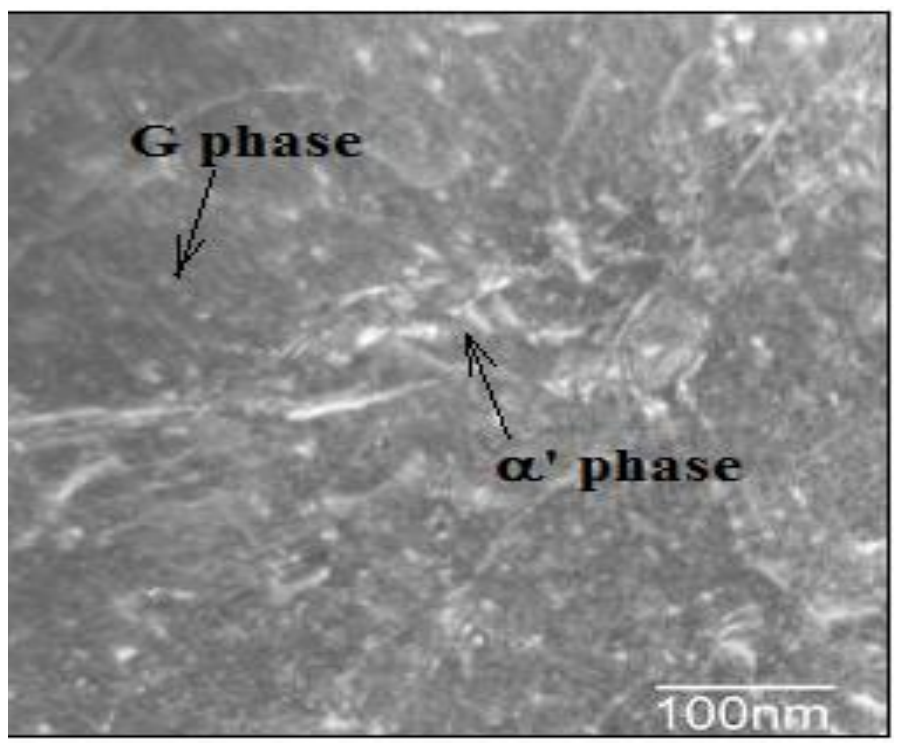

Figure 7. TEM analysis of the sample SAF 2205 aged at $400^{\circ} \mathrm{C}$ for $5000 \mathrm{~h}$.

transition peak, $\mathrm{i}_{\mathrm{a} / \mathrm{p}}$, led the phase changes that occur during the ageing, increasing the interface area of matrix/phase and therefore of alloying-depleted regions area in this interface, while hampering the passivation process and thus favored the mass loss.

\section{ACKNOWLEDGMENT}

This work was conducted with the efforts of members of the Laboratory of Materials, Federal Technological University of Paraná - Câmpus Cornelio Procópio - PR Brazil.

\section{REFERENCES}

Fang YL, Liu ZY, Xue WY, Song HM, Jiang LZ (2010). Precipitation of secondary phases in lean duplex stainless steel 2101 during isothermal ageing. ISIJ Int. 50(2):286-293.

Ghosh SK, Mondal S (2008). High temperature ageing behavior of a duplex stainless steel. Mater. Characterization 60:1776-1783.

Hamaoka T, Nomoto AK, Dohi K, Soneda N (2012). Effects of aging temperature on G-phase precipitation and ferrite-phase decomposition in duplex stainless steel. Philos. Mag. 92(34):43544375.

Han D, Jiang, Y, Deng B, Zhang L, Zhang W, Li J (2009). Effect of aging time on electrochemical corrosion behavior of 2101 duplex stainless steel. Acta Metallurgica Sinica 45:919-923.

lacoviello F, Casari F, Gialanela S (2005), Effect of $475^{\circ} \mathrm{C}$ embrittlement on duplex stainless steel localized corrosion resistance. Corros. Sci. 47:909-922.

Kuri SE, May JE, Souza CAC, Nascente PAP, Soares P, Lepienski CM (2010). Effect of Thermal Aging Conditions on the Corrosion Properties and Hardness of a Duplex Stainless Steel. Mater. Res. 13(4):431-436.

Moreno JRS, Francisco JCS (2013); Significant Increase in the Hardness of the Ferritic Phase due to Structural Changes at low Temperatures in Duplex Stainless Steels. Mechanika J. 19(3):344348

Shi Sk, Yan J, Zhang Y, Wang YS, Wang J (2012). The microstructure evolution of 2205 stainless steel in long-term aging at $500^{\circ} \mathrm{C}$. Nuclear Eng. Des. 250:167-172.

Zhang L, Jiang Y, Deng B, Zhang W, Xu J, Li J (2009). Effect of aging on the corrosion resistance of 2101 lean duplex stainless steel. Mater. Characterization 60:1522-1528. 